\title{
ÚLTIMA DÉCADA COMO UNA REVISTA ESPEJO DEL CAMPO DE ESTUDIOS EN JUVENTUDES ENTREVISTA A ÓSCAR DÁVILA LEÓN
}

En el marco de la celebración de los 25 años de la Revista Última Década, coincidiendo con el número 50 , nos ha parecido relevante volver sobre los orígenes y la trayectoria de la publicación. Buscamos conocer cuáles son las motivaciones que incidieron en su surgimiento, así como elementos del contexto que gatillaron apostar por esta publicación, y la reflexión del equipo editorial para que se mantenga vigente durante un cuarto de siglo. De igual forma, nos interesa conocer cuáles podrían ser, en el escenario actual, algunos desafíos para este medio de divulgación sobre juventud.

Se trata de una publicación del Centro de Investigación y Difusión Poblacional de Achupallas (CIDPA), en Viña del Mar, V Región. El primer número de la revista (Año I, $\mathrm{N}^{\circ}$ I), está fechado en diciembre de I993, siendo anual la periodicidad durante los tres primeros años. Así, en 1996 ya comienza a tener una frecuencia semestral (Año $4, \mathrm{~N}^{\circ}{ }_{4}$ ). Inicialmente sus temas se ubicaban en las experiencias de actores sociales, su organización, acción política, historia, despliegues de movimientos, educación popular, educación y formación social, promoción y desarrollo; siendo actores jóvenes el sector en que se fue haciendo foco dada la experiencia que CIDPA desplegaba en el territorio. Los primeros trabajos tenían formato de ensayos, notas de investigación, sistematizaciones de experiencias; lo que poco a poco fue modificándose en el tiempo, hasta llegar a ser una revista especializada en juventudes y con dedicación a la divulgación de resultados de investigaciones sobre juventudes.

En los primeros años la responsabilidad de la edición era ejercida de manera rotativa según la temática de los números, así estuvieron en este rol: Oscar Dávila, Astrid Oyarzún, Luis Vildósola, Igor Goicovic, Jorge Marín, entre otros. En este trayecto Oscar ha sido un actor clave, ya que además de ser parte del equipo fundador fue el editor responsable desde I997 hasta el 20I3. Por ello 
hemos conversado con él, para que, de primera fuente, nos contribuya con sus percepciones sobre la historia de la Revista.

Klaudio Duarte: Oscar, nos interesa conocer cómo surge la iniciativa de llevar adelante la revista, considerando el contexto de final de la dictadura, primeros años de gobiernos civiles en la década del noventa.

Óscar Dávila: Los orígenes de la revista precisamente son -en cuanto a su discusión inicial- de comenzar a editar alguna publicación, finalmente terminó siendo la Última Década. Con los compañeros de cidpa, en aquellos tiempos, estuvimos más o menos un año preparando lo que iba a ser posteriormente la revista. El primer número apareció a finales del año I993, en diciembre. Nos costó un tiempo, porque el propósito inicial de, yo creo que, de toda revista del mundo de las ciencias sociales y las humanidades, se vincula siempre con un déficit y con una pretensión, con alguna intencionalidad. El déficit era precisamente tanto por el hecho de las circunstancias más bien sociopolíticas que atravesaba el país en ese entonces, como también este déficit en términos de investigación sobre actores sociales, por decirlo en un sentido amplio de la expresión. Creo que partimos con esas dos premisas bastante sencillas, bastante universales y comunes y corrientes. Y que dentro de nuestro trabajo también como cidpa en aquellos entonces, en Achupallas, teníamos mucho que ver con el tema de la redemocratización del país, de las comunidades, de las organizaciones comunitarias con las que trabajábamos ahí en ese sector poblacional de Viña del Mar Alto.

Nos interesaba aportar también algún tipo de reflexión, algún tipo de perspectiva, de sistematización también, de ensayo, más que única y exclusivamente en lo que podía convertirse en algún momento en una revista con algún carácter más científico, como se les suele llamar y que tuviera fundamentalmente que ver con resultados de investigación, tanto investigación más teórica como investigación más aplicada.

En un comienzo era una revista de reflexión, de ensayo, de miradas reflexivas, de sistematización de nuestras mismas prácticas, y los viejos temas de objeto-sujeto, y cómo nos ubicábamos y posicionábamos también tanto desde nuestro trabajo social en un sentido amplio y nuestro trabajo comunitario, cómo lo podíamos volcar en una sistematización y una reflexión más sistemática, que pudiera tener algún sentido difundirlo y preparar algunas premisas que estábamos desarrollando en aquellos tiempos.

Ese es como el origen de esta revista Última Década, que incluso su nombre tuvo algo hasta casi como anecdótico, en un sentido milenarista; faltaba poco para el fin de siglo y milenio, por el 2000, faltaban siete años en ese entonces y no tuvo que ver con ningún acabo de mundo, ni cosas por el estilo. El nombre surgió de un sorteo, un concurso que hicimos interno, quedó como 
Última Década; incluso cuando terminó la década, milenio, dijimos «tenemos que cambiarle el nombre», pero lo dejamos así.

Klaudio Duarte: ¿Y esta fue la única publicación que idearon?

Oscar Dávila: Dentro de esa pretensión original de editar esta revista sobre actores sociales, posteriormente al convertirse en una revista dedicada a temas de estudio sobre juventudes, siempre tuvimos la pretensión de que necesitábamos editar tres revistas. Incluso hicimos un intento de una segunda que tenía que ver con temas educacionales, que se llamó Diversia y que no tuvo larga vida. Después nos faltaba también volver a los orígenes, y volver a otra, una tercera revista vinculada con temas de ciencias sociales en general, cosa que no hemos hecho, y no sé si lo vayamos a hacer, habiendo otras revistas que cubren ese espacio.

Klaudio Duarte: Entonces la revista no nace originalmente dedicada a temas de juventudes, porque CIDPA, ahí en el sector de Achupallas, tenía un trabajo en varios ámbitos.

Oscar Dávila: No fue pensada en lo que finalmente se convirtió por otras derivaciones. Era una revista de ciencias sociales se podría decir, en un sentido tan amplio de la expresión, con un vínculo muy particular, con un énfasis, con un eje, si pudiéramos decirlo, sobre actores sociales. Si tuviese que ponerle un nombre a aquello, o por lo menos al debate, la discusión que existían en aquellos tiempos, principios de la década de los noventa, sobre la importancia de retomar, reflexionar, teorizar sobre lo que podríamos estar llamando actores sociales. Por los mismos déficit que existieron fruto de la dictadura, la larga dictadura, y donde estas reflexiones no fueron tan desarrolladas como en la década de los noventa. Después fue perdiendo un poco de vigencia y tiene esta suerte de salto de la investigación como la reflexión.

Partió como una revista de ciencias sociales, de temas sociales, incluso mucho más amplio, donde si uno revisa los primeros números, sin hacer una cronología ni nada por el estilo, eran temas que estaban bastante más cercanos de nuestros quehaceres y nuestras preocupaciones. O sea, había un tema importante de actores sociales, todos los que se te podían ocurrir en aquellos tiempos, algunos siguen muy vivos en cuanto a la visibilidad más académica en ese plano: los temas de género, que en ese entonces se llamaban más bien de «actores sociales mujeres»; los jóvenes estaban, sin duda; también movimiento de pobladores, sin casa, allegados, comercio informal; en fin, un retrato de familia de los años noventa. También con alguna impronta que comenzábamos a tener alguna intervención de trabajo con el mundo educacional, las escuelas y los liceos, por ahí había estas variantes desde la perspectiva más educativa, tanto de sujetos niños, niñas, como jóvenes, como lo que significaba la dinámica propia de los establecimientos educacionales también viviendo una nueva época en aquello. 
Klaudio Duarte: Hasta la revista $N^{\circ} 9$ del año 1998, los temas eran bien amplios, en el sentido que tú señalabas de ciencias sociales, actoría social, y ya en mayo de 1999 empiezan a concentrarse en juventud, ¿cómo se transforma en una revista que se especializó en temas de juventudes?, ¿por qué dentro de esta gama de ámbitos y actores que tú mencionas, los mundos juveniles terminaron siendo el sujeto en torno al cual giró la revista?

Oscar Dávila: Fue una decisión bastante pragmática. Nos vimos involucrados hacia finales de la década del noventa, incluso si mal no recuerdo fue en el año 2000 el primer número que correspondió ya exclusivamente a temas de juventud, y fue porque prácticamente todo nuestro quehacer tenía que ver con temas de juventud, esa fue una decisión muy práctica al respecto. Ya había otra realidad en el país, otra realidad en nosotros como institución, ya no estábamos tomando muchos otros temas, nos dedicamos a juventudes, actorías juveniles, tanto del punto de vista educacional, como del punto de vista de actorías, en los ambientes no escolares. Entonces comenzamos a tener esa doble dimensión, de este sujeto juvenil escolar y no escolar.

Klaudio Duarte: Óscar, y entrando en el 2000 para acá, ¿qué acontecimientos marcarías tú, en la trayectoria de la revista, que te parezcan relevantes para la conversación actual sobre juventudes?

Oscar Dávila: Uno puedo decir desde las temáticas, por decirlo en una manera laxa, sean más conceptuales, sean más metodológicas, sean las formas de abordar a estos sujetos jóvenes. Ha habido una suerte de continuidades y cambios también, y en algunos ha sido más cambios que continuidades quizás, en cuanto a los énfasis que pudieron haber tenido estas temáticas, y cómo, también en un lenguaje muy laxo, cómo se ponen de moda y pasan de moda ciertas temáticas vinculadas con lo juvenil, las juventudes. Creo que la revista es un buen ejemplo, que si pudiéramos especular, la revista podría ser una suerte de espejo de lo que se está investigando y lo que se está ensayando, sistematizando, escribiendo, opinando sobre materia de juventudes en Chile, y quizás con algún alcance latinoamericano. Entonces podría mencionar el hecho de la poca continuidad que ha habido de ciertas temáticas, en un sentido de conocimiento más acumulado; hay temas que aparecen y desaparecen, que es una tremenda área de vacancia, como dicen los colegas en Argentina, el hecho que no hemos seguido históricamente en estos temas. O sea, uno perfectamente puede pensar en los temas de tribus juveniles, tribus urbanas, hoy día no es tema, no está en ninguna agenda investigativa, no está puesto como un tema, como lo estuvo Io, I5 años atrás, en los 2000, que hubo incluso un conjunto de, tanto equipos de investigación, instituciones, investigadores e investigadoras que se volcaron un buen tiempo en lo que significó estos temas de la subjetividad juvenil. 
Un segundo aspecto, no solamente lo temático, sino que la mirada de un punto de vista quizás más metodológico y conceptual, donde comienza a tener una suerte de preeminencia las dimensiones más cualitativas y las dimensiones de la intersubjetividad en lo juvenil. También es un descubrimiento, de visiones un poco más duras, más estructurales que pueden haber habido, más ensayísticas, inclusive, que pudieran haber habido en lo que corresponde a investigación sobre juventudes y el reflejo que se dio también en la revista durante ese tiempo, los 2000 hacia adelante, si podemos hacer esa suerte de cronología.

Un tercer aspecto que también rescataría, vinculado con esto que mencionaba con las modas que van apareciendo, los temas, es porque hay razones, cómo se construye este conocimiento, acumulado o no en materia de juventud, y tiene que ver eso con la agenda pública que esté en boga, o sea, podemos pensar perfectamente todo lo que significó, si queremos ser pretensiosos, un diseño de políticas públicas dirigido a jóvenes, que también es más bien en ofertas programáticas. Eso alimentó miradas al respecto. Aparecen los jóvenes en desventaja social, aparecen los jóvenes vulnerables, aparecen todo el discursito, que podríamos decir hoy día del sename, todo el discurso del déficit de los muchachos, la deuda social con los jóvenes, todo eso alimenta una buena producción que uno la puede perfectamente recoger en muchos trabajos de la revista.

Este ámbito, que tiene que ver precisamente con las políticas públicas, muy vinculado a lo anterior, tanto agenda pública como políticas públicas, es un buen elemento para la reflexión, para el debate, para la evaluación, poco para la teorización, definición de marcos más conceptuales, en dónde se insertan. Hasta el día de hoy, inclusive, donde toda esta dimensión de la política pública no necesita muchos marcos conceptuales, son más bien marcos metodológicos, marcos de planificación, etcétera; que es sin duda un déficit que no favorece mucho la reflexión y la crítica que puede presentarse al respecto.

Otro aspecto en esa misma línea que estaba mencionando, tiene que ver con la visibilidad pública de determinados actores y temáticas, y eso sin duda lo vemos con absoluta claridad, en lo que ha tenido que ver con movimientos estudiantiles: secundarios y universitarios, eso ha alimentado, yo me atrevería a decir, hasta el día de hoy, una tremenda producción. Una tremenda producción en cuanto a temáticas que ya se trasladan a la dimensión de la expresividad, la visibilidad, la acción política, la acción de grupalidades al respecto, y nos alejamos también, como eje principal, de lo que significa las dimensiones más estructurales, de existencia, de estos actores o sujetos jóvenes.

Desde el año 2000 en adelante han convivido estas dimensiones, pero también creo que es necesario decirlo, en el hecho de que no solamente por tema de definición editorial de la revista, la revista publica lo que hay, o sea, la revista no es un generador por sí sola de contenidos, pues el comité editorial no genera propuestas investigativas ni nada por el estilo, más allá de cada uno individualmente. 
Entonces, en esta suerte de reflejo o espejo, obviamente si uno lo ve en una larga duración, son áreas de vacancia, son déficit de la investigación social sobre juventudes en Chile, el tema es que quienes nos dedicamos a estas dinámicas, no hemos afrontado. Tenemos déficit en todo lo que significa la dimensión económica, más estructural de los jóvenes, el mundo del trabajo, la dimensión estructural del trabajo, más allá de algunos aprontes desde las subjetividades y los sentidos que le atribuyen los jóvenes al mundo del empleo. Creo que esos dos temas, la dimensión económica; no hay economistas, por ejemplo, de profesión, que se dediquen al tema de juventudes. Algunos muy particularmente, unas dimensiones cuantitativas que tienen que ver con el tema del mercado laboral en general, pero no más que eso. El tema de salud, el tema sanitario, tanto de salud mental, salud física de los jóvenes, exceptuando el tema de salud sexual y reproductiva, tampoco ha sido un tema que ha estado presente; tampoco hay, por corrientes también profesionales, investigativas, o sea, me da la impresión que nunca un médico ha publicado algún trabajo en la Última Década, nunca un psiquiatra; y son campos de la salud que hay investigaciones al respecto, pero que no ha habido estos puentes y vasos comunicantes entre distintos campos en las esferas profesionales y de la investigación. Creo que son los déficits al respecto. El tema familia, tampoco ha sido, desde todas las miradas multidisciplinarias que se puedan, que puedan confluir en esta dimensión de familias, tampoco ha sido un tema muy desarrollado. Un último para mencionar, y que seguramente hay muchos más, tiene que ver con este mundo de las nuevas tecnologías; está un asunto bastante experimental en ese plano, que precisamente no ha pasado el rigor metodológico, más investigativo por precisamente usar las mismas fuentes que está investigando, es como tautológico, o sea, si usted investiga sobre Facebook a través de Facebook, eso no tiene mucha validez [risas], dicho de manera jocosa, o sea, usted me dice los jóvenes cuántas horas pasan jugando con estas cosas, comunicando, vamos a la investigación más tradicional, a lo mejor también del punto de vista de la investigación en ciencias sociales, en estas materias, va a ver que pegarse un ajuste, quizás que a lo mejor el instrumental conceptual, técnico, metodológico, a lo mejor va a tener que adecuarse respecto a nuevas realidades que a través de la investigación más tradicional, quizás es muy difícil de asir, de recoger, de apuntar.

Los grandes momentos, principalmente del punto de vista de las temáticas, han ido variando, algunas desaparecen, no vuelven a aparecer más; y lo otro, un tema que sí ha tenido una permanencia en el tiempo, es la dimensión de lo juvenil en el contexto escolar, de la institución escuela-liceo; eso ha sido bastante permanente en el tiempo, de repente demasiado por el hecho de que se tiende a pensar, algunos investigadores, investigadores que porque trabajan con actores, sujeto jóvenes que son estudiantes secundarios por ejemplo, eso tiene que ver con algo de estudiar juventudes, y a lo mejor estamos sólo estudiando interacciones en el aula de clases, y correspondería a otros campos más 
apropiados. Pero ha habido una preocupación importante en temas institucionales, en este caso en la dimensión educativa.

Klaudio Duarte: Es interesante esta imagen que usaste de la Revista como un espejo, que va catalizando la dinámica que se da dentro de quienes hablan de juventudes. Ahora, este conjunto de ausencias que tú mencionaste en términos temáticos, esta no profundización metodológica, esta dificultad por la teorización y mucho más opción de partir desde la empírea, hasta encontrarnos con investigaciones tautológicas dices respecto de cómo se plantean y cómo se reflexionan. ¿Tú apostarías porque se ha ido constituyendo un campo de estudio de juventud en Chile?, ¿y cómo la revista podría haber aportado en ese sentido durante estos 25 años?

Oscar Dávila: Sí, yo creo que para que exista una revista con un perfil y un destino, y un propósito más o menos específico, que puede ser el caso de la Última Década, tiene que haber alguna suerte de comunidad o suerte de campo, o por lo menos a lo Bourdieu, comunidad de hablantes, o sea gente que esté hablando más o menos sobre lo mismo, sino no tiene sentido y no tiene público. Entonces, distinto es que pueda la revista ser un espejo, un reflejo, de lo que está pasando, por lo menos en la dimensión chilena y latinoamericana si queremos ampliarlo un tanto más, y eso yo creo que nos remite precisamente a la pregunta de qué tanto, individual, colectivamente, nosotros mismos, quienes en Chile investigamos más o menos permanentemente estos temas y dinámicas de juventud, se ha logrado conformar un determinado campo, y cuál sería ese campo y/o comunidad.

Yo creo que sí existe, siendo pretensioso como campo, con tremendas deficiencias que seguramente cada cual podrá compartir, sobre todo en términos de continuidades y permanencias. O sea, si pudiéramos decir hay que contar con los dedos de una mano, dos manos, de colegas que han estado por lo menos los últimos diez años intentando investigar en materia de juventud, y publicar en materia de juventud también, son poquísimos, es muy poca gente en una mirada de larga duración. Hay gente que entra, que sale, pero el día de mañana está dedicado a otro tema, en otras dinámicas, se cambió de trabajo. Hay pocos centros académicos, de investigación, que tengan como propósito principal la actoría juvenil o las juventudes; están ustedes, el Núcleo de Juventudes de la Universidad de Chile; el Centro de Juventud de la Universidad Cardenal Silva Henríquez; el Centro de Estudios Socioculturales (cesc). O sea, hay tres, cuatro, cinco... A veces adolecemos también de las capacidades, las competencias, los financiamientos para volcarnos aquí. Pero sin desviarme en el hecho de qué configura en este campo, este campo obviamente no son solamente personas, son soportes desde las institucionalidades, o sea, un campo fundamentalmente debería ser una comunidad de hablantes, de personas que se puedan relacionar, que puedan investigar, que puedan debatir, que puedan discutir, que puedan publicar, etcétera. Eso no se puede hacer de manera autónoma. 
Tiene que haber un soporte fundamentalmente institucional, y en el caso de lo que estamos volcados, eso tiene mucho que ver con un soporte investigativo de las universidades. Las universidades es el grueso de las investigaciones en Chile, el 99,9\% se hace en universidades, y algún centro por ahí, pero normalmente tiene una perspectiva académica en ese plano. Las universidades no tienen la capacidad, no tienen el financiamiento, dentro de lo que significan estas políticas precisamente, fundamentalmente de Conicyt y todos sus instrumentos que tiene al respecto, incluyendo el apoyo bastante distorsionado a publicaciones científicas chilenas que tampoco son un soporte, un apoyo muy interesante.

Difícilmente las universidades por sí mismas pueden mantener algunos Centros de investigación, Centros de estudio, Centros de difusión, de publicación-investigación, y eso es parte de la conformación del campo. Por ejemplo, es necesario resaltar en el último tiempo, no sé si es único, no quiero exagerar tampoco, es precisamente el Proyecto de Juventudes, de Anillos en Investigación en Ciencias Sociales, creo que esa experiencia institucional de coordinación de I5 investigadores, es casi la única experiencia que podemos nombrar en muchísimo tiempo, no sé si ha habido otra, lo otro son iniciativas más particulares. Entonces, este es un campo débil, un poco famélico, en que cada cual tiene que buscar su forma de financiamiento, para generar algún tipo de investigación; algunos muy dedicados a lo que significa el plano más de los quehaceres en políticas públicas, que muchas veces no tienen ni el propósito, ni el tiempo para el tema de la investigación, o el tema de la publicación.

Y lo otro son las dimensiones que, también en esto de campo, ponerlo en esta discusión viejísima, este locus consultorial que nos decía Salazar hace años, que eso también de algún modo ha mellado la capacidad de más reflexión, de teorización, de publicación. El locus consultorial, son pequeños problemas, pequeñas soluciones, es demasiado empírico otras veces, donde no permite generar y aportar a un ciclo más dinámico en perspectiva de conformar precisamente esta pretensión de campo, una comunidad que pueda verse en eso. Otras iniciativas que son positivas en el hecho de fortalecer este campo, tienen que ver con los grupos de trabajo, algunos congresos, el de Sociología Chilena, el alas (Asociación Latinoamericana de Sociología) que tiene su capítulo de juventud, que también dinamiza en torno a eso, el Congreso de Psicología que también tiene alguna dimensión, capítulo o grupo de trabajo sobre juventud, que pueden ir dinamizando precisamente este campo.

También lo último a mencionar en esto, es la cantidad impresionante de muchachos y muchachas graduados, universitarios, que hacen sus tesis en juventudes, es impresionante, pero son muchos de ellos «entrada y salida» $\mathrm{o}$ «debut y despedida»; o sea, hacen sus tesis al respecto, pero no son personas que se van a dedicar posteriormente, precisamente por la inexistencia más consolidada de un campo donde puedan también incorporarse ellos, hasta en un punto de vista laboral. Nosotros tuvimos una opción preferencial por investigadores 
jóvenes, tratar de ser consecuentes con nuestros propios discursos en los autores y autoras, y también es algo rescatable el que muchos jóvenes, fundamentalmente tesistas, publicaron y fueron, en algunos casos, el inicio de una carrera investigativa. En el acceder a publicar en la Revista Última Década, siempre la evaluación fue distinta, diferenciada, y no hacerles competir con investigadores de más oficio. Rescato ese tema que, de hecho, he conocido a varios muchachos, que ya no son muchachos y muchachas, que fue una cosa súper significativa, de muy jóvenes, 23, 24 años, publicaran en la revista, les significó algo muy importante para ellos. Sobre todo a tiempos actuales, donde proliferan de manera significativa investigadores con necesidad de publicar en revistas indexadas.

Klaudio Duarte: Óscar, hay un acontecimiento importante, a propósito de esto que planteabas del Proyecto Anillo Juventudes, cuando ustedes como institución deciden entregar la revista para que sea gestionada por parte del equipo de ese Proyecto Juventudes. ¿Cuáles son las motivaciones que los llevaron a tomar esa decisión?

Oscar Dávila: La motivación está muy vinculada a lo que mencioné anteriormente. De estas comunidades de hablantes o de campo, por sí solo cada uno seguramente no puede, esto hay que difundirlo más, cada vez más, hay que profesionalizarlo cada vez más también, hay que ampliarlo, hay que internacionalizarlo. Fue, incluso en términos bastante ideales, de que se diera la circunstancia de ver una comunidad de colegas, digamos amplia, con una buena parte del país, de muchas instituciones, que pudiera precisamente hacerse cargo de ello. No por un desprendimiento nuestro que no queríamos seguir con ella, sino que veíamos cuál era la mejor alternativa para proyectarla en el tiempo. Siempre consideramos que tenía un sentido la revista, y que lo sigue teniendo; seguimos pensando que tiene esa potencia, hay muy pocas revistas de habla castellana en América Latina, de unas cuantas importantes que habían, ahora hay dos.

El propósito nuestro fue traspasar, precisamente esta suerte de posta, de poder ampliarla, poder seguir consolidándola, seguir aportando también como uno más dentro de los pares, esto del Proyecto Anillos. Y sin duda ha sido una experiencia positiva, que se ha logrado lo que uno más o menos pensaba, con las limitaciones que tiene también de ser una publicación, de las limitaciones de financiamiento que tenemos cada uno de nosotros como instituciones no son menores, los temas de difusión, los temas de dedicación a esto, pero siempre bajo el principio -en lo coloquial-y el propósito de la revista es presentar buenos trabajos, buenas reflexiones. Ese es el propósito, así como muy simple, que después que nos hemos tenido que meter en una tecno-burocracia media salvaje, en la que están involucradas las publicaciones indexadas: no por más indexaciones, publican mejores trabajos las revistas.

Pero el propósito es ser ese espejo, ese reflejo de lo que se está investigando. El día que se deje de investigar, se deje de debatir, se deje de reflexionar, obviamente no va a tener sentido alguna publicación de esta naturaleza. 
Klaudio Duarte: En el contexto que tú ya varias veces has hecho referencia de esta suerte de mercado de la publicación, de «locura por la publicación», que debilita tanto la densidad de lo que se plantea, ¿qué proyecciones le ves tú a lo que está pasando con esta Revista?

Oscar Dávila: Un primer punto, estoy absolutamente agradado y apoyo con firmeza las aperturas a las publicaciones en acceso libre, el open access es una maravilla, es una maravilla a ser valorada; no son todas, pero la tendencia va rapidísima hacia allá. Incluso las revistas que tienen un sentido comercial, de lucro, que son las grandes transnacionales de las publicaciones, anglosajonas particularmente, inglesas, norteamericanas y alguna otra europea por ahí que van a acceso abierto es una maravilla. Después es un problema por el hecho que ya hay demasiado, y humanamente es imposible estar leyendo todo lo que se publica, eso ya es una contradicción en Wikipedia, antes había que tener plata para comprar una enciclopedia, hoy día no es necesario, no hay tiempo para leer tanta cosa.

Lo segundo es una suerte de atomización de los campos disciplinarios en cuanto a publicaciones, cada vez hay más publicaciones de nichos muy particulares, que seguramente tienen que ver con los campos y espacios de investigación, reflexión, en ámbitos de las ciencias sociales y humanidades; en otras áreas seguramente también la tendencia es la misma: una tendencia hacia mucha especialización, discursivamente dicho, pero con una dificultad de poder consolidar el campo, por lo mencionado anteriormente. Ahora, en las publicaciones electrónicas, ya son prácticamente todas electrónicas, más allá de los romanticismos de la revista en papel impreso, hay demasiado de eso, es un campo a competir muy complejo, sobre todo por no estar ocupando o pensar que no es necesario usar mucha estrategia de marketing, sea digital o sea del que sea, pero las publicaciones pasan a ser también un producto a ser vendido, aunque sea gratis o a costo cero.

No tenemos muchas evaluaciones de audiencia, diría la televisión, algunos indicadores solamente, que no sean los indicadores de indexación y citación, que son bastante parciales y muy particulares, que no permite ver la forma que están llegando ciertas publicaciones a un público que está interesado en aquello. Lo sabemos algunas veces por los reportes de los servidores que nos arrojan donde están alojadas las revistas, en el caso particular de la Última Década, o de las publicaciones Scielo, que tienen buenos reportes del punto de vista cuantitativo, de cuánta gente accede, graba un artículo, no sabemos si lo lee o no, pero en fin, hay algunos indicadores que nos pueden ir dando un acercamiento y que nos permite también ir mejorando, tanto en las estrategias más de difusión, de promoción, como también las mismas características de las revistas. Las revistas no son sometidas a procesos de evaluación, de evaluación de audiencias, que no sería malo pensar en hacer evaluaciones en esa línea. 
Un desafío particular para la revista, lo veo por el lado de una mayor presencia latinoamericana, ampliar un poco más este campo. Hay, últimamente, mucho de colegas argentinos, por ejemplo, es porque están en un proceso parecido al chileno en que hay que publicar. Una muy baja presencia de otras realidades, en México también, por ser una potencia investigativa en el área de las Américas, también tiene una presencia un poco mayor, pero casi inexistente de otros países. Brasil es un caso aparte que ha ido teniendo presencia también más allá de las diferencias de idioma, que sí se pueden hacer perfectamente esta interconexión de idioma, entre el portugués y el castellano, que se publican en portugués los artículos que aparecen en su lengua original. Brasil tiene una investigación en juventud, tremenda, enorme, pero que a veces se ve limitado por el tema idiomático, que no es ningún problema, ha habido unos muy buenos trabajos también publicados en la revista, hay que ponerle algo más de atención. Quizás, algunos vínculos más particulares, en esta misma línea de los campos, al respecto, y que en otros países prácticamente muy poco, ya sea Perú, Bolivia, incluso Uruguay que tiene una ocupación interesante en temática de juventudes también. El tema de la internacionalización yo creo que es importante.

Lo otro que ha sido siempre una discusión permanente en las revistas temáticas, el potenciar ciertas perspectivas, ciertos temas, ahí es donde viene la dimensión de los monográficos, que a lo mejor se puede ensayar precisamente por temas que no sean a libre disposición, o libre demanda, lo que llegue en ciertas temáticas. A lo mejor se pueden intencionar ciertos temas que pueden ser relevantes, dentro de la discusión social en materia de juventud, y que se puede direccionar un poco más, a lo mejor un número, algunos temas, alguna sección, de estos déficits o áreas de vacancia que se tiene.

Otro asunto es cómo se entra, no me gusta mucho la palabra, a competir en este mercado de la aldea global electrónica de publicaciones, que son infinitas, uno leerá dos, tres, cuatro cosas, pero es imposible todas. Y eso pasa por consolidar también ese mismo campo, donde por lo menos quienes se sienten parte, objetiva o subjetivamente, de este campo de juventudes o estudio sobre juventudes, es una referencia obligada la Última Década desde hace bastante tiempo, no sólo porque no hayan muchas, sino porque han habido contribuciones importantes que han sido referencia obligada dentro de las muchas discusiones que existen sobre la materia. 